\title{
Ground-Water Activation from the Upcoming Operation of MI40 Beam Absorber
}

\author{
C.M. Bhat. and A.L. Read \\ Fermi National Accelerator Laboratory \\ P.O. Box 500, Batavia, Illinois 60510
}

September 1996 


\section{Disclaimer}

This report was prepared as an account of work sponsored by an agency of the United States Government. Neither the United States Government nor any agency thereof, nor any of their employees, makes any warranty: express or implied, or assumes any legal liability or responsibility for the accuracy, completeness or usefulness of any information, apparatus, product or process disclosed, or represents that its use would not infringe privately owned rights. Reference herein to any specific commercial product, process or service by trade name, trademark, manufacturer or otherwise, does not necessarily constitute or imply its endorsement. recommendation or favoring by the United States Government or any agency thereof. The liews and opinions of authors expressed herein do not necessarily state or reflect those of the United States Government or any agency thereof.

\section{Distribution}

Approved for public release: further dissemination unlimited. 


\title{
Ground-water Activation from the Upcoming Operation of MI40 Beam Absorber
}

\author{
C.M. Bhat and A. L. Read \\ Fermi National Accelerator Laboratory \\ P.O. Box 500. Batavia. Illinois $60.510^{*}$
}

\section{Introduction}

During the course of normal operation, a particle accelerator can produce radionuclides in the adjacent soil and in the beam line elements through the interactions of accelerated particles and/or secondary particles produced in the beam absorbers, targets, and sometimes elsewhere through routine beam losses. The production and concentration of these radionuclides depends on the beam parameters such as energy, intensity, particle type. and target configuration. The radionuclides produced in the soil can potentially migrate to the ground water. Soil activation and migration to the ground water depends on the details of the local hydrogeology:

Generally, very few places such as the beam stops, target stations, injection and extraction sectors can have high enough radiation fields to produce radionuclides in the soil outside the enclosures. During the design, construction. or an upgrade in the intensity of existing beams, measures are taken to minimize the production of activated soil.

The only leachable radionuclides known to be produced in the Fermilab soil are ${ }^{3} \mathrm{H},{ }^{7} \mathrm{Be} .{ }^{22} \mathrm{Na},{ }^{45} \mathrm{Ca}$ and ${ }^{54} \mathrm{Mn}$ and it has been determined that only ${ }^{3} \mathrm{H}$, and ${ }^{22} \mathrm{Na}$, because of their longer half lives, and greater leachabilities, may significantly impact ground water resources [1].

In the past, Fermilab has developed and used the Single Resident Well Model (SRW.M) [1.2] to estimate the ground water activation. Recently, the Concentration Model (CM), a more realistic method which depends on the site hydrogeology has been developed to decide the 
shielding requirements of the high radiation sites, and to calculate the ground water activation and its subsequent migration to the aquifer $[3,4]$.

In this report, the concentration of radionuclide released to the surface waters and the aquifer around the MI40 beam absorber [5] are calculated. Subsequently, the ultimate limit on the primary proton beam intensity to be aborted on the Main Injector beam absorber is determined.

\section{Fermilab Main Injector and MI40 Beam Absorber}

The Fermilab Main Injector (F.MI) is a $8-150 \mathrm{GeV}$ proton synchrotron that is being built as a high intensity $150 \mathrm{GeV}$ proton injector to the Tevatron with a capability of providing $120 \mathrm{GeV}$ proton beam yearround for fixed target experiments. A schematic view of the FMII is shown in Fig. 1. The Main Injector beam absorber is built near the MI40 straight section and has the base floor elevation of $214.884 \mathrm{~m}$ $(70 \mathrm{Jt})$. This elevation is lower than the elevation of any other beam absorbers at Fermilab. The base concrete slab thickness is $1.016 \mathrm{~m} \mathrm{(3}$ ft 4 in).

Originally, the beam absorber was designed [5] to receive about $3.0 \times 10^{13} 150 \mathrm{GeV}$ protons per machine cycle including a safety margin. The expected annual beam aborts $[6, \tau]$ are given in Table I. Since the Fermilab accelerator complex is planning on upgrading its beam intensity by over a factor of three beyond the Fermilab Run II plans [8], the core of the MI40 beam absorber has been redesigned to stand as much as $1.0 \times 10^{14} 150 \mathrm{GeV}$ protons per machine cycle continuously without being compromised [9]. The upgraded beam intensity in the FMI might lead to increased aborted beam beyond that shown in Table I. Under these conditions, it is shown that the present design is sufficient to keep the discharge of the activation products into the surface waters and the aquifer, below acceptable, regulatory limits. 
Table I. Annual aborted proton beam on the MI40 beam dump [6.7].

\begin{tabular}{|l|r|}
\hline Beam Energy & Annually Aborted Beam \\
\hline $8 \mathrm{GeV}$ & $3.1 \mathrm{E} 18$ \\
$120 \mathrm{GeV}$ & $3.1 \mathrm{E} 18$ \\
$150 \mathrm{GeV}$ & $0.3 \mathrm{E} 18$ \\
\hline $150 \mathrm{GeV}^{*}$ & $\begin{array}{r}\text { Energy Averaged } \\
\text { Aborted Beam } \\
3.52 \mathrm{E} 18\end{array}$ \\
& \\
\hline
\end{tabular}

* The energy averaged annually aborted beam on the beam absorber is estimated using a scaling law of $E^{0.605}$ for the dependence of energy deposition [10].

Current U. S. Environmental Protection Agency regulations specify the maximum concentration in public drinking water supplies for the accelerator produce radionuclides [1]. The present limit for ${ }^{3} \mathrm{H}$ is 20 $p C i / m l-y r$ ( see Table II).

Figures 2(a), (b) and (c) show plan, elevation and longitudinal sectional views of the MI40 beam absorber [5]. The core of the beam absorber will be a graphite cylinder placed inside a $0.305 \mathrm{~m} \times 0.305$ $\mathrm{m} \times 3.353 \mathrm{~m}$ aluminum box. A schematic view of the core box of the MI40 beam absorber is shown in Fig. 2(d). This aluminum box is surrounded by $0.84 \mathrm{~m}$ thick steel, and $1.1 \mathrm{~m}$ thick concrete. The aluminum container will be cooled by a $40^{\circ} \mathrm{C}$ low conductivity closed loop water system. The overall dimension of the beam absorber is $10.7 \mathrm{~m}$ long and 
$4.26 \mathrm{~m} \times 4.26 \mathrm{~m}$ cross section. The entire beam absorber is installed on $0.58 \mathrm{~m}$ high concrete support legs.

\section{Hydrogeology at the MI40 Beam Absorber Site}

As mentioned earlier the migration of the radionuclides in the soil to the aquifer depends on the soil properties and the hydrogeology of the site. Topography at Fermilab is relatively flat. The average surface elevation is about $225.5 \pm 1.5 \mathrm{~m}(740 \pm 5 \mathrm{ft})$ above sea level $[11,12]$. There are several man-made ponds and creeks on site. The ponds are considered to be perched and are not reflective of site ground water. The primary purpose of these ponds is to provide cooling water for the magnets, and for fire protection purposes.

Ten drinking water wells are present on the Fermilab site. All of these wells are located in the Silurian Dolomite bedrock. The Silurian Dolomite is generally $30 \mathrm{~m}(100 \mathrm{ft})$ to $60 \mathrm{~m}(200 \mathrm{ft})$ thick. Figure 3 shows the locations of these wells on the Fermilab site. The well at F17 location is the nearest one to the MI40 beam absorber location. A model which characterizes the geology, hydrology and hydrogeochemistry of the Fermilab site was developed [12] based on available data.

A geologic cross section of the MI40 beam absorber region given in reference [12] is shown in Fig. 4. The top elevation of the Silurian Dolomite in this region is at about $207.4 \mathrm{~m}(667 \mathrm{ft})$. Therefore, the thickness of the silty clay is $7.5 \mathrm{~m}(24.6 \mathrm{ft})$. However, the potentiometric map, derived from the information from the well at F17, indicates the water level in the dolomite is at $209.4 \mathrm{~m}(68 \mathrm{ft})$. The latter elevation is selected as the elevation of the aquifer to make a conservative estimate of the concentration of radionuclides in the ground water [13]. 


\section{Model Used to Determine the concentration of the ra- dionuclides in the Groundwater}

Determination of the concentration of radionuclides in the ground water due to the operations of the MII0 absorber involves two steps. First, modeling of the production of these radionuclides through the interaction of radiation with the soil. The second step involves the modeling of the transport of these radionuclides through the soil layers to the nearest aquifer. A Monte Carlo model of interaction of high energy radiation with matter is used for the first step. Later, the leaching of the induced soil radioactivity into the ground water is estimated using the current Fermilab standard model (C.M).

\subsection{Calculation of Radio-isotope Production Using the Computer Code CASIM}

To calculate the amount of ${ }^{3} \mathrm{H}$ and ${ }^{22} \mathrm{Na}$ produced in the soil around the MI40 beam absorber. the Monte Carlo simulation computer code CASIM $[14,15]$ was used. CASIM simulates the derelopment of the hadronic cascade within the beam absorber, and those particles that leak through the shielding around the absorber activating the surrounding soil. The program uses inclusive distributions of particle yields as a function of the angle and momentum from inelastic particle-nucleus interactions and simulates the average development of inter-nuclear cascades when high energy particles are incident on a large target of arbitrary geometry and composition. 'Star densities'. i.e. nuclear interaction densities, as a function of three-dimensional coordinates and particle type throughout the target are computed by the program. Using the probabilities for production of the ${ }^{3} \mathrm{H}$ and ${ }^{22} \mathrm{Na}$ nuclei per star (see second column of Table II), the total amount of individual radionuclei in the soil can be estimated.

Figure 5 shows the contours of equal star density ( in units of stars/ml /incident particle) in the MI40 beam absorber and the soil around the 
absorber for $150 \mathrm{GeV}$ incident protons. Even though CASIM can perform the calculations with exact geometry, the MI40 beam absorber calculations have been carried out in a cylindrically symmetric approximation to collect more statistics at a faster calculational speed.

Table II. Production probabilities, mean life, leach-ability factor for radioactive nuclei produced in the soil and the DOE/EPA allowed concentrations.

\begin{tabular}{|l|l|l|l|r|}
\hline Nuclei & $\begin{array}{l}\text { Production } \\
\text { Probability } \mathrm{K}_{i} \\
\text { (per star) }\end{array}$ & $\begin{array}{l}\text { Leach-ability } \\
\text { Factor } \mathrm{L}_{i}\end{array}$ & $\begin{array}{l}\text { Mean life } \\
\tau_{i}(\mathrm{yr})\end{array}$ & $\begin{array}{r}\text { Allowed } \\
\text { Concentrations } \\
G_{i}(p \mathrm{C} i / m l-y r)\end{array}$ \\
\hline${ }^{3} \mathrm{H}$ & 0.075 & 0.9 & 17.7 & 20.0 \\
${ }^{22 \mathrm{Na}}$ & 0.02 & 0.135 & 3.75 & 0.2 \\
\hline
\end{tabular}

4.2 Modeling of the migration of radioisotopes to the aquifer using the Concentration Model (CM)

In this section the recently approved concentration model [1-4] will be used to determine concentrations of ${ }^{3} \mathrm{H}$ and ${ }^{22} \mathrm{Na}$ in the aquifer and estimate the allowed number of protons per year on the MI40 beam absorber.

This model uses the maximum star density in uncontrolled soil at a point closest to the beam absorber. This quantity is extracted from Fig. 5. According to this model the initial concentration of the $i^{\text {th }}$ radioactive nuclide $C_{i}^{\text {initial }}$ in units of $(p C i / m l-y)$ is given by,

$$
C_{i}^{\text {initial }}=\frac{N_{p} \cdot 0.019 \cdot S_{\text {Max }} \cdot K_{i} \cdot L_{i}}{1.17 \times 10^{6} \cdot \rho \cdot \omega_{i}}
$$


where

$N_{p}$ is the annual proton intensity on the beam absorber $(3.52 \times$ $10^{18} / \mathrm{yr}$ ) (from Table I).

$S_{M a x}$ is the maximum of the star density/incident proton produced in the unprotected soil (i.e.. the soil surrounding the beam absorber or beam absorber enclosure) For the MI40 beam absorber we have $S_{\text {Max }}$ $=5 \times 10^{-10} \mathrm{star} / \mathrm{ml} /$ proton.

$\rho$ is the soil density $(2.25 \mathrm{gm} / \mathrm{ml}$ for moist soil $)$,

$\omega_{i}$ is the weight of the water divided by the weight of the soil that corresponds to $90 \%$ leaching $\left(0.27\right.$ for ${ }^{3} \mathrm{H}$ and 0.52 for $\left.{ }^{22} \mathrm{Na}\right)$.

With the above parameters the initial concentrations are $C^{\text {initial }}\left({ }^{3} \mathrm{H}\right)$ $=3.16(p C i / m l-y r)$ and $C^{\text {intial }}\left({ }^{22} \mathrm{Na}\right)=0.07(p C i / m l-y r)$.

The final concentration in the ground water. $C_{i}^{\text {final }}$, is related to the initial concentration by:

$$
C_{i}^{\text {final }}=C_{i}^{\text {initial }} \cdot R_{\text {till }} \cdot R_{\text {mix }} \cdot R_{\text {dolomite }}
$$

where $R_{\text {till }}$ is a reduction factor due to vertical migration and radioactive decay occurring during transport to the glacial till from the lowest boundary of the ' $99 \%$ volume" 1 to the top of the dolomite aquifer. It can be calculated according to [2],

$$
\begin{gathered}
R_{\text {till }}\left({ }^{3} H\right)=1.0 \cdot e^{(-0.3 \cdot d)} \\
R_{\text {till }}\left({ }^{22} N a\right)=1.0 \cdot e^{(-0.92 \cdot d)}
\end{gathered}
$$

where $\mathrm{d}$ is the distance from 1.84 meters below the point of maximum star density to the aquifer. $R_{m i x}$ is a reduction due to the mixing of the water containing the accelerator produced radioactivity with water at the glacial till/dolomite interface. $R_{\text {dolomite }}$ is a reduction due to the

\footnotetext{
${ }^{1}$ the ' $99 \%$ volume' is defined as the total volume of the unprotected soil which contains $99 \%$ of the total stars produced outside the controlled (or protected) region of a beam absorber.
} 
mixing and radioactive decay occurring in the transport to the Fermilab site boundary or nearest well. The most conservative assumption is to assume instantaneous mixing, which results in assuming both $R_{m i x}$ and $R_{\text {dolomite }}$ to be unity. Distance $\mathrm{d}$ is taken as 2.6 meters for the MI40 beam absorber. Thus the final concentrations are

$$
\begin{aligned}
C^{\text {final }}\left({ }^{3} \mathrm{H}\right) & =1.44 \mathrm{pCi} / \mathrm{ml}-\mathrm{yr} \\
C^{\text {final }}\left({ }^{22} \mathrm{~N} a\right) & =0.005 \mathrm{pC} i / \mathrm{ml}-\mathrm{yr} .
\end{aligned}
$$

According to reference [2] the sum of the ratios of concentrations to their allowed regulatory limits must be less than one. to insure that the annual $4 \mathrm{mrem} / \mathrm{yr}$ limit for community drinking water supplies is not exceeded:

$$
\sum_{i=1}^{n} \frac{C_{i}}{G_{i}} \leq 1.0 .
$$

Where $G_{i}$ is the allowed concentration of the $i^{\text {th }}$ radio-isotope, given in Table II. Using equations (1). (2) and the above equation, the maximum number of protons annually allowed on the MII0 beam absorber is about $3.63 \times 10^{19}$.

A calculation carried out using the Single Resident Well Model $[1,2]$ which does not take into account of the detailed hydrogeology of the site would underestimate the limit of protons per year by a about factor of five.

\subsection{Discharge of Radio-isotopes to the Surface Waters}

Leaching of radio-isotopes produced in the soil, into the surface waters should also be considered in the design of a beam absorber. There is a specific standard for the discharge of radionuclides to the surface waters (DOE Order 5400.5, Chapter II Section 1, and Chapter III). According to this regulation the allowed concentration limit for tritium is 2000 $p \mathrm{Ci} / \mathrm{ml}$, and $10 \mathrm{pCi} / \mathrm{ml}$ for ${ }^{22} \mathrm{Na}$, where the total limit is calculated using Eq. (4). 
To determine the concentration of radionuclides leaching into the surface waters the hydrology and flood plain associated with the site should be taken into account. At the Main Injector site the surface drainage is towards the Indian Creek and Fox River. Hydrology studies have shown [12] the peak discharge to be 618 cubic feet per second, including the 100-year flood case. Analyses of the Fermilab surface waters, Fox River and DuPage River waters and their sediments did not detect any concentrations of ${ }^{3} \mathrm{H}$ and ${ }^{22} \mathrm{Na}$ [16]. This survey will continue periodically. The discharge of the radionuclides to the surface waters in the case of MII40 beam absorber has been estimated by using the concentration model.

A useful feature of the CMI model is that $C^{\text {intial }}$ is the concentration of the $i^{t h}$ radionuclide right outside the absorber. Therefore, this value can be compared to the concentration limits for the surface waters. Using the results from the previous section we have.

$$
\begin{gathered}
C_{\text {Surface }}^{\text {Max }}\left({ }^{3} \mathrm{H}\right)=2.94 \mathrm{pC} \mathrm{C} / \mathrm{ml} \\
C_{\text {Surface }}^{\text {Hax }}\left({ }^{22} \mathrm{Na}\right)=0.06 \mathrm{pCi} / \mathrm{ml} .
\end{gathered}
$$

These amounts are negligible compared to the allowed "surface water" limits. Therefore. the limiting intensity for the protons dumped at MI40 beam absorber is that obtained from the "ground water" calculations.

\section{Summary}

The concentration of radionuclides in the ground water due to the operation of the MI40 beam absorber has been calculated using the Fermilab Concentration Model [1-4]. The discharges to both the aquifer and the surface waters have been estimated.

The allowed limits of concentration of these two radionuclides $\left({ }^{3} \mathrm{H}\right.$ and ${ }^{22} \mathrm{Na}$ ) have been used to estimate the maximum allowable number of protons to be sent to the MI40 beam absorber. The results of these 
calculations are summarized in Table III. Thus, one can send up to $3.63 \times 10^{19}$ protons $150 \mathrm{GeV} / \mathrm{yr}$ to the MI40 beam absorber without contaminating the ground or surface waters, i.e., a factor of ten above the previously estimated annual aborted beam shown in Table I.

Table III. Allowed number of protons on the MI40 Beam Dump. $C_{i}$ 's are calculated using $3.2 \tau \times 10^{18}$ protons on the Beam Absorber at 150 $\mathrm{GeV}$.

\begin{tabular}{|l|l|l|r|}
\hline & Model & $\sum_{i=1}^{n} \frac{C_{i}}{G_{i}}$ & $\begin{array}{r}\text { No. of allowed } \\
\text { protons on the } \\
\text { Mito Beam absorber }\end{array}$ \\
\hline Ground Water & C.I & $0.09 \tau$ & $3.63 \times 10^{19} / \mathrm{yr}$ \\
\hline Surface Water & - & $\leq 8 \times 10^{-3}$ & Not a limiting quantity \\
\hline
\end{tabular}

\section{Acknowledgments}

We wish to thank D. Bogert, W. B. Fowler, S. D. Holmes, P. S. Martin and J. D. Cossairt, A. J. Malensek, A. A. Wehmann and A. van Ginneken for helpful discussions. In particular, we wish to thank Kamran Vaziri for his critical reading of this paper and many useful comments. 


\section{REFERENCES}

1. Fermilab Radiological Control Manual

2. J.D. Cossairt ' Use of a Concentration-based Model for Calculating the Radioactivation of Soil and Groundwater at Fermilab' Environmental Protection Note 8, (1994).

3. A.J. Malensek et al. T.M 1850

4. A.J. Malensek et al. TM 1851

5. C.M. Bhat, MINote on MI40 Beam-absorber and IEEE conf. Rept.

6. Fermilab Main Injector Preliminary Safety Analysis Report, (PSAR) dated 4-21-1992.

7. Main Injector Design Report 1994.

8. Fermilab Run II Hand Book (1995)

9. M. A. Reichanadter, C. M. Bhat, C. Crawford and P.S. Martin (private communication) (1995),

10. A. Leveling (private communication)-'Dugan's Criteria'

11. Summary of Radionuclide Transport Modeling for Ground Water at the Fermi National Accelerator Laboratory: Batavia Illinois, by Woodward-Clyde (Aug. 1993)

12. Environmental Assessment Proposed Fermilab Main Injector Project DOE/EA - 0543

13. J.D. Cossairt, (private communication) (1996).

14. A. Van Ginneken, 'CASIM Program to simulate Transport of Hadronic Cascades in Bulk Matter, Fermilab report FN-272 (1975),

15. A. Van Ginneken and M. Awschalom, 'High Energy Particle Interactions in Large Targets' Vol.1. Fermilab (1975).

16. A. Leveling (Private Communication)(1996). 


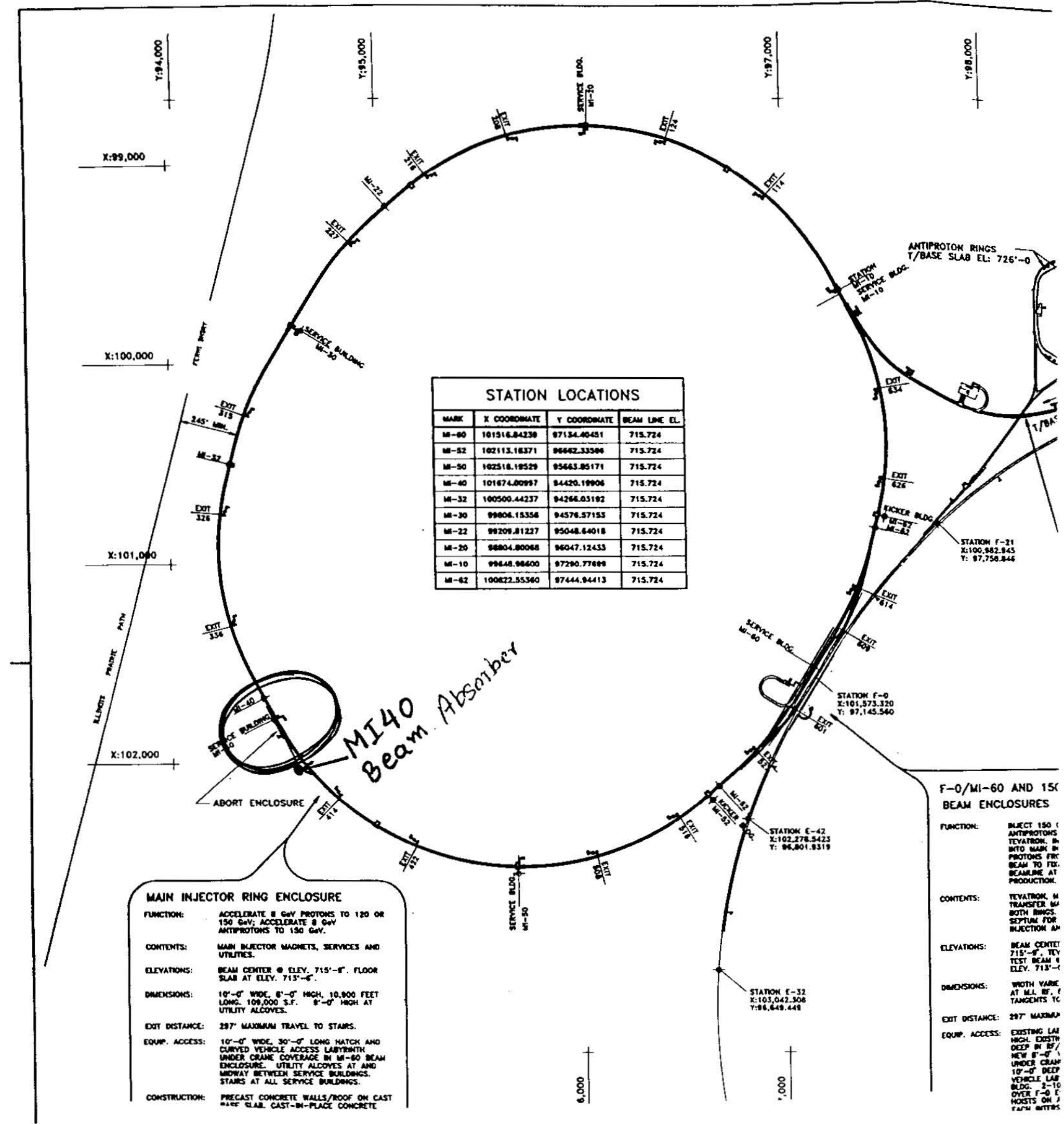

Figure 1. Plan view of Fermilab Main Injector. The location of MI40 beam absorber is indicated.

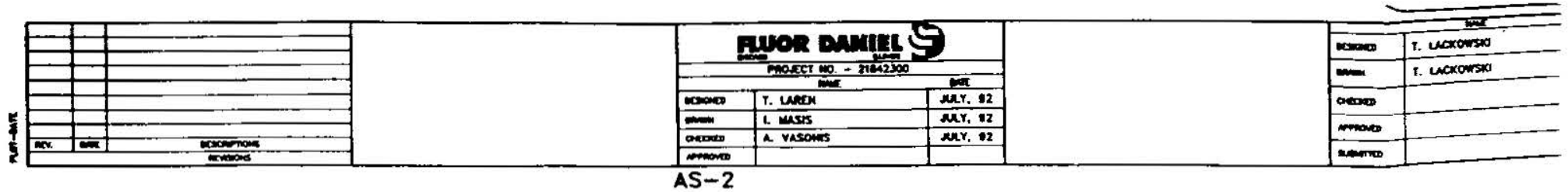




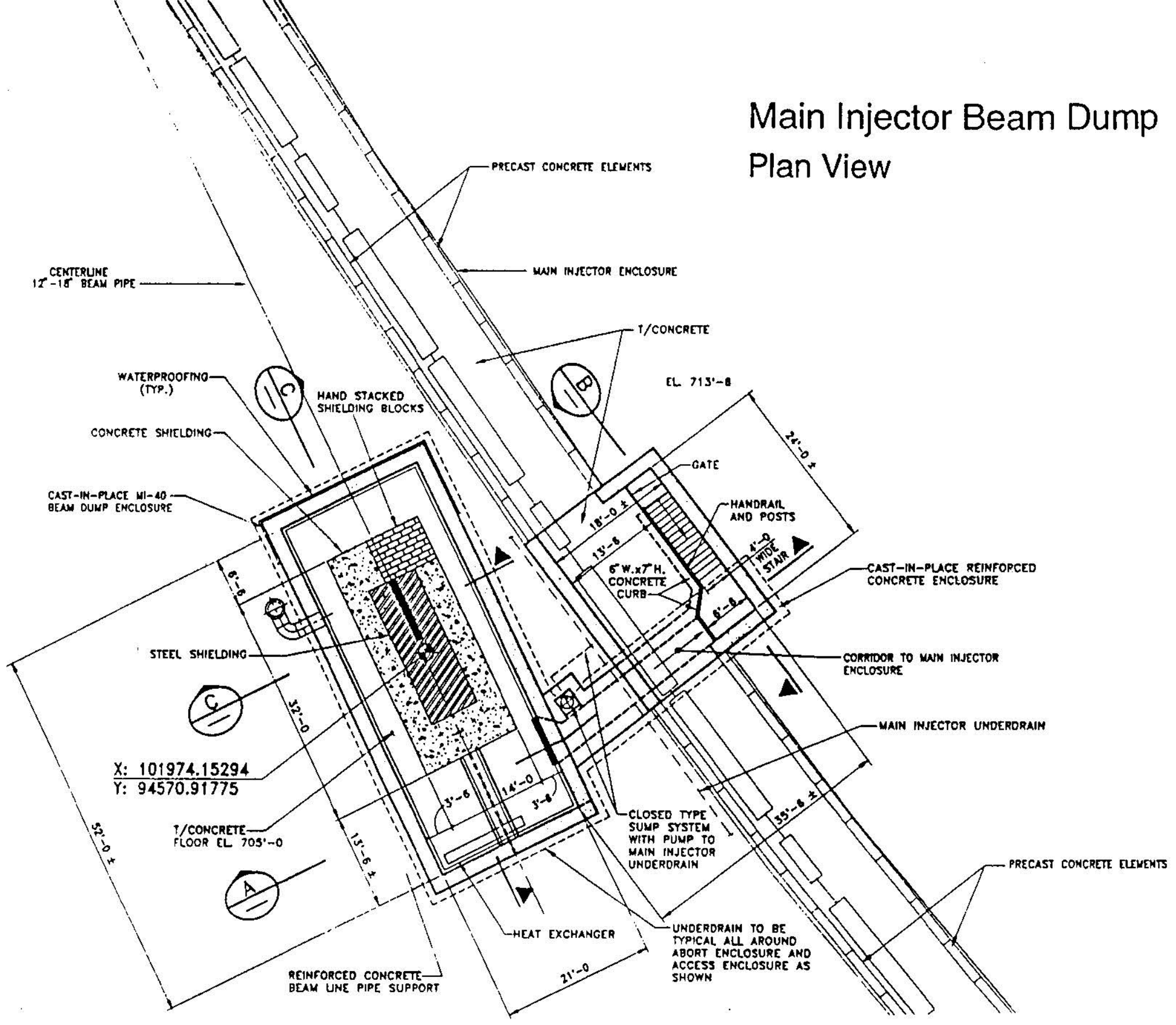

Figure 2(a). Plan view of the Main Injector beam absorber enclosure at MI40. 


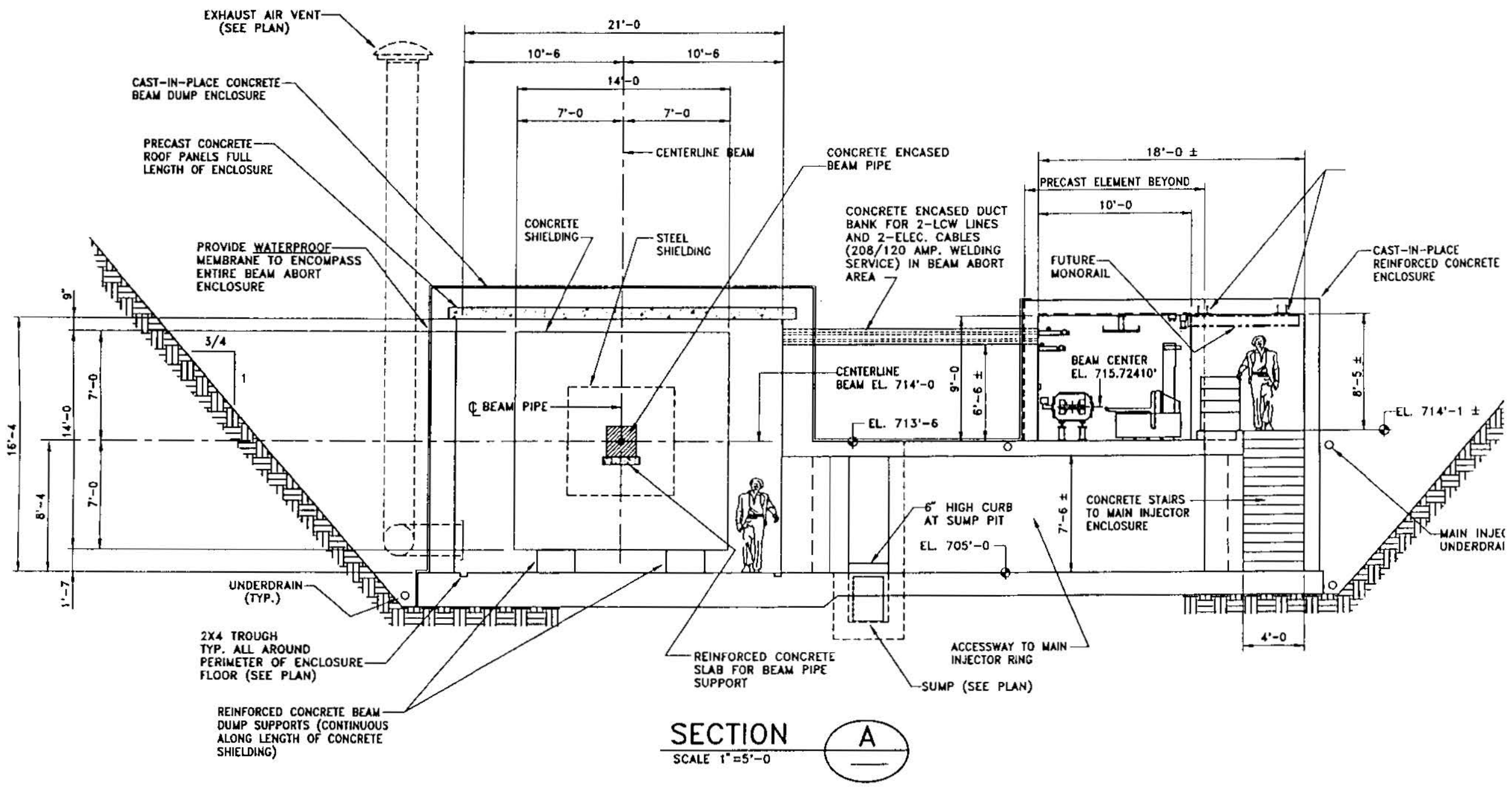

Figure 2(b). Elevation view of the Main Injector beam absorber enclosure at MI40. 


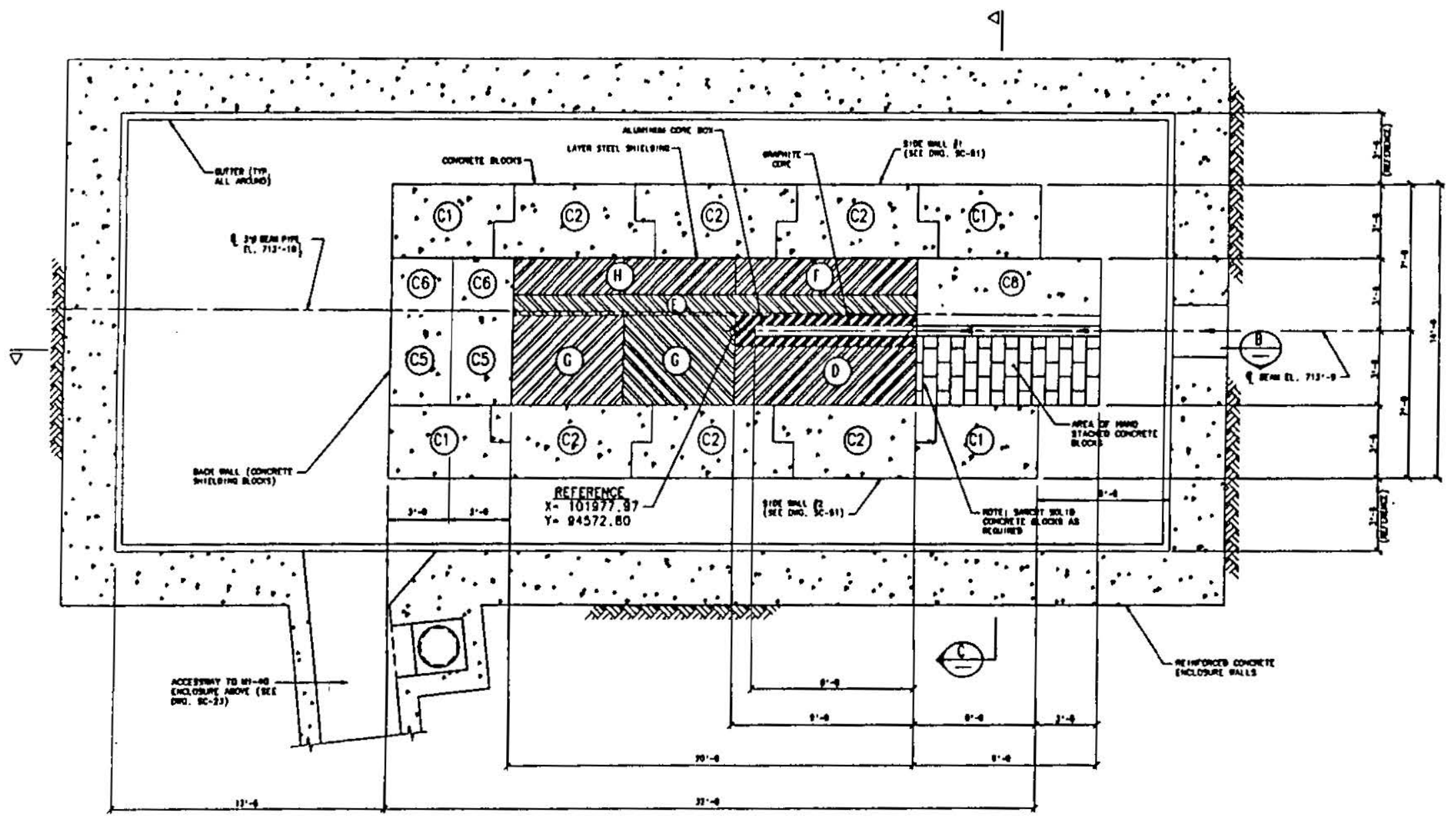

PLAN SECTION THRU BEAM ABORT OUMP

Figure 2(c). Longitudinal sectional view of the Main Injector MI40 beam absorber. 


\section{MI40 Beam Absorber Core Box}

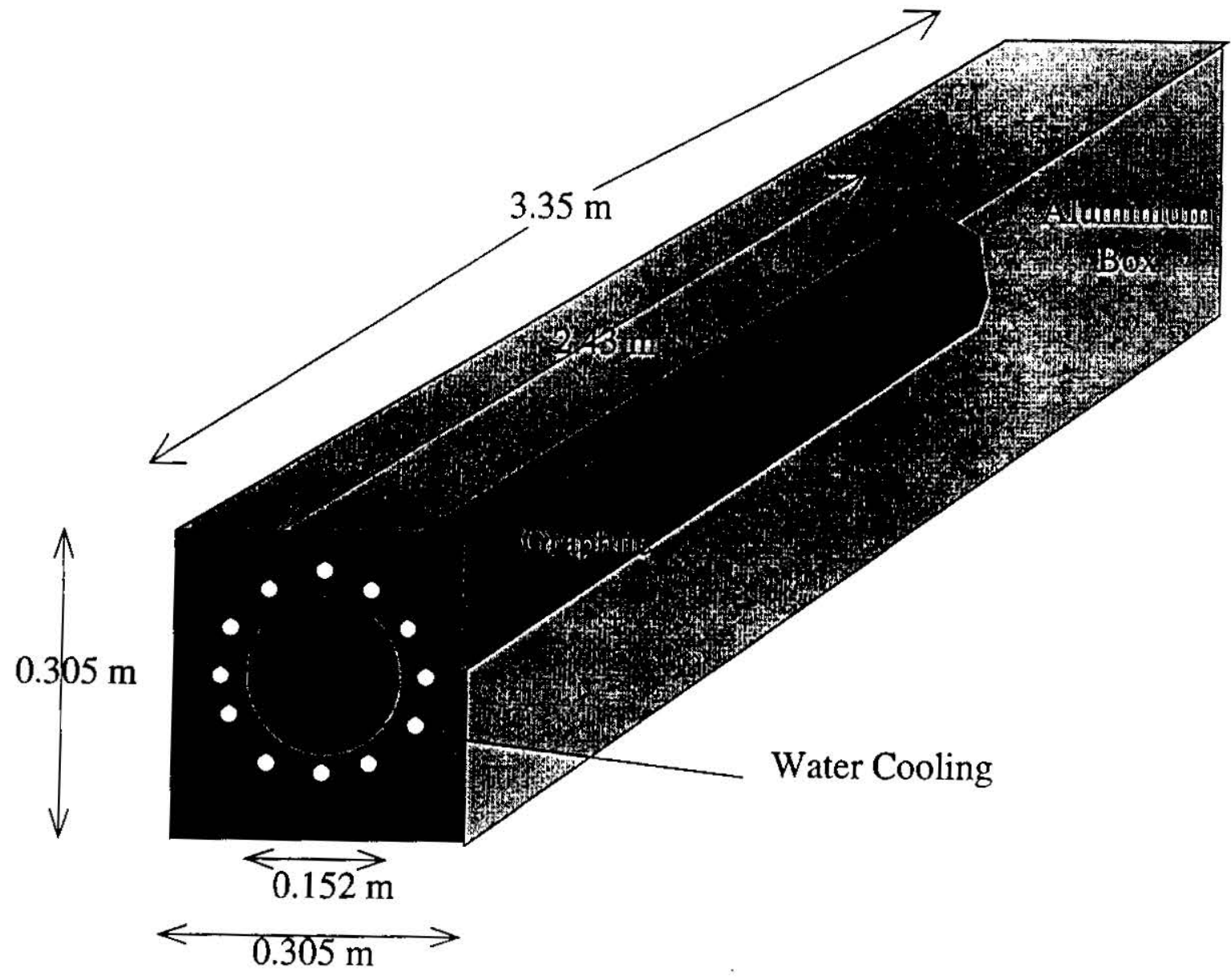

Figure 2(d). A schematic view of the Main Injector beam absorber core box. The central cylindrical graphite has a dimension of radius $=$ $7.62 \mathrm{~cm}(3 \mathrm{in})$ and length $=2.43 \mathrm{~m}(8 \mathrm{ft})$. The graphite is imbeded in $0.305 \mathrm{~m} \times 0.305 \mathrm{~m} \times 3.35 \mathrm{~m}$ aluminum box. The aluminum box is cooled using a $40^{\circ} \mathrm{C}$ low conductivity closed loop water system. 
Figure 3. Well locations at the Fermilab site.

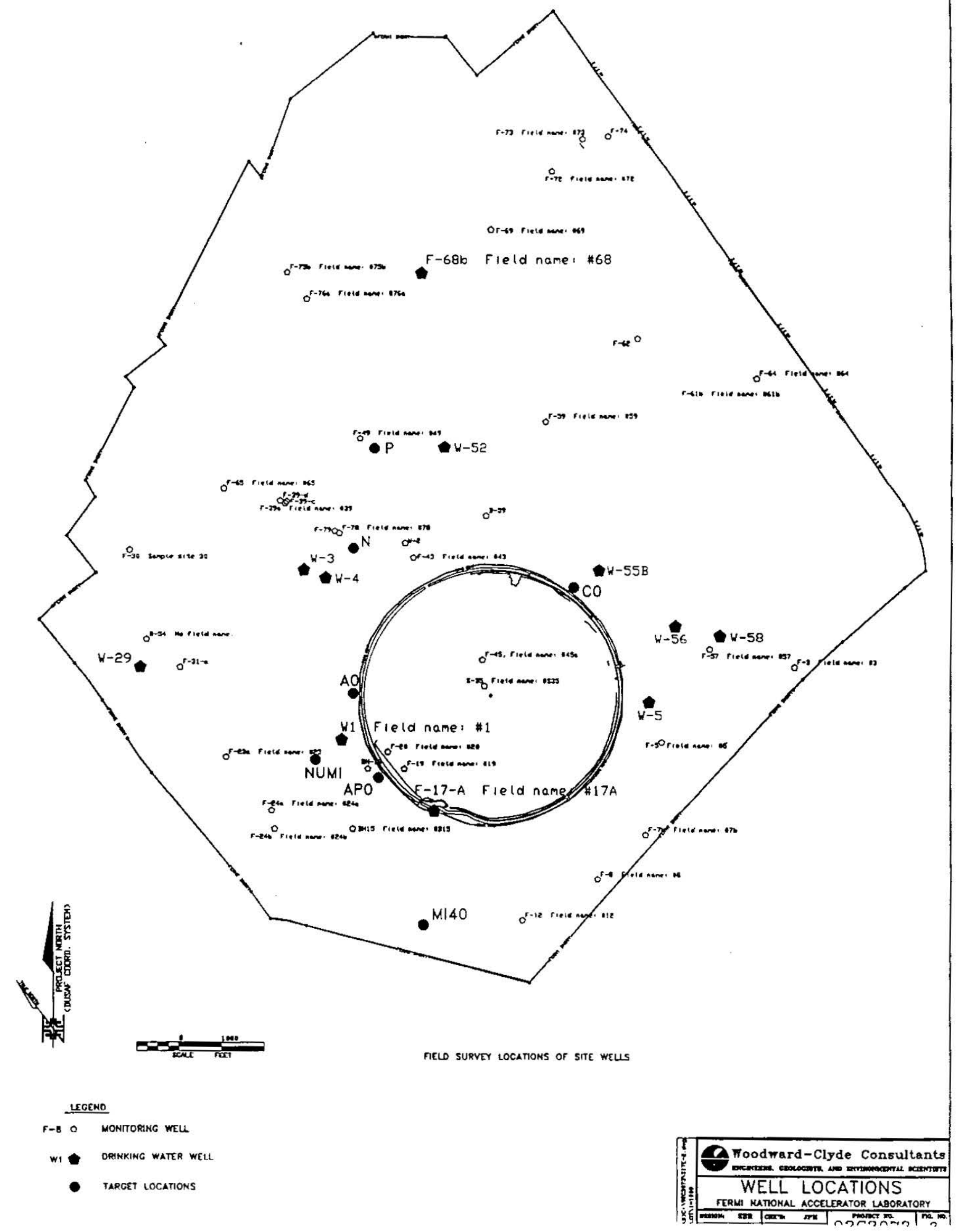




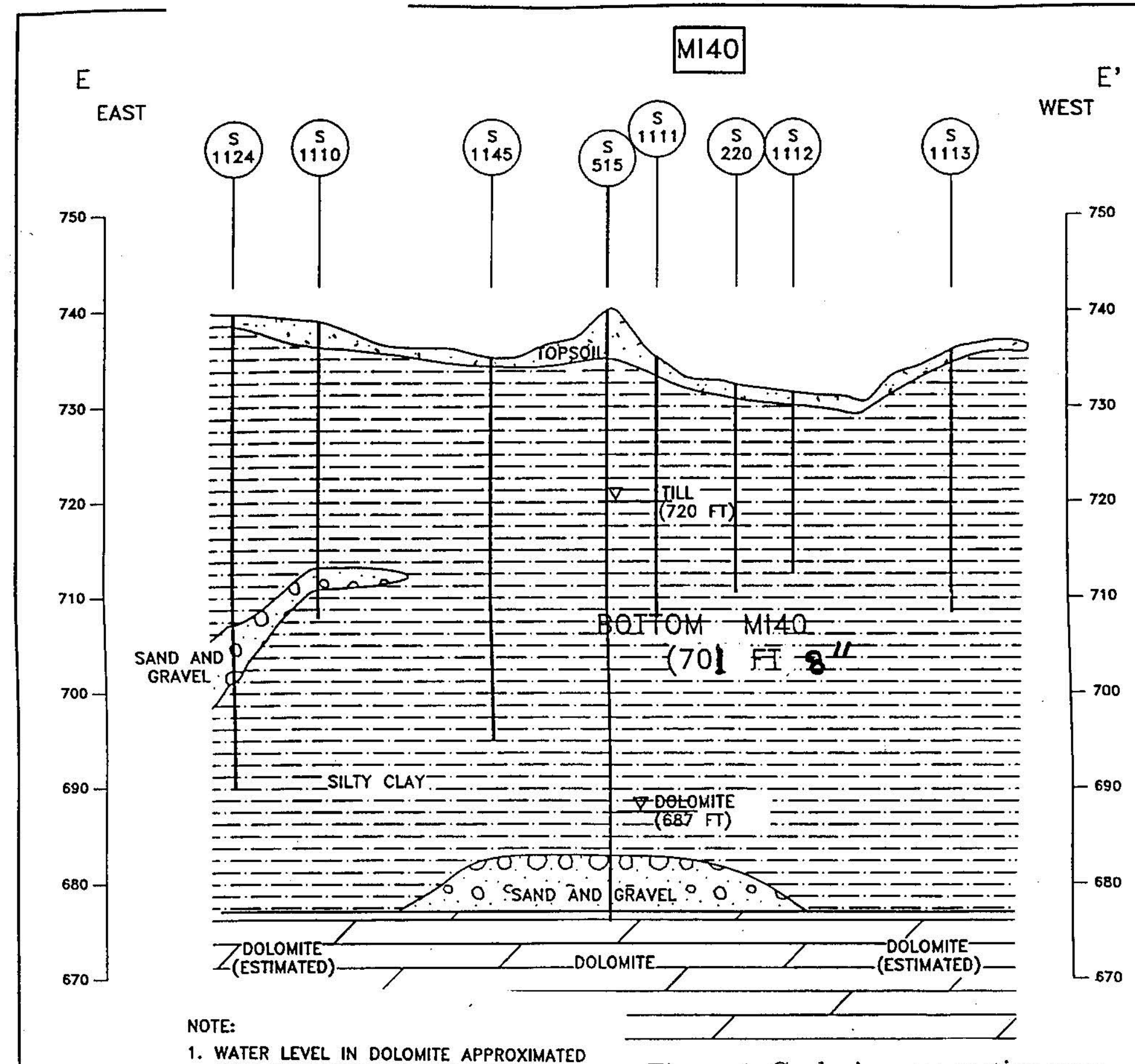

1. WATER LEVEL IN DOLOMITE APPROXIMATED FROM POTENTIOMETRIC MAP (FIGURE 5)

2. WATER LEVEL IN TILL APPROXIMATED FROM COLOR CHANGE IN STRATIGRAPHY INDICATED ON BORING LOG FOR BORING NEAR MI4O.

Figure 4. Geologic cross section near MI40 Beam Absorber. 
ISODOSE CONTOURS DUE TO HADRONS IN THE MI BEAM DUMP (VERTICAL PLANE)

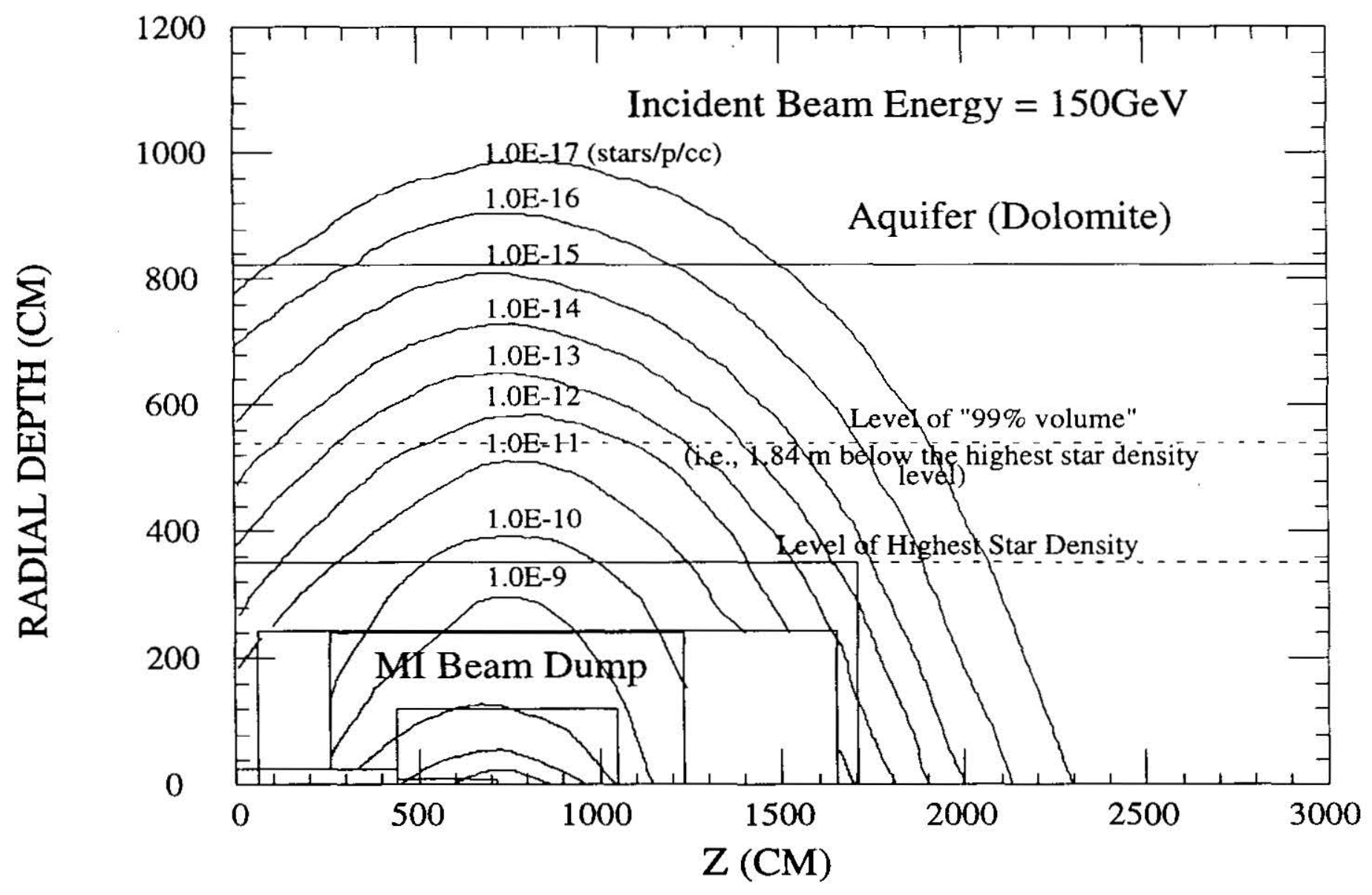

Figure 5. Results of CASIM calculations for MI40 Beam Absorber. 